OPEN ACCESS

Edited by:

Helmut Jonuleit,

Johannes Gutenberg-University

Mainz, Germany

Reviewed by:

Ciriaco A. Piccirillo,

McGill University, Canada

Urszula Krzych,

Walter Reed Army Institute of

Research, USA

*Correspondence:

Karsten Mahnke

karsten.mahnke@med.

uni-heidelberg.de

Specialty section:

This article was submitted to Immunotherapies and Vaccines,

a section of the journal

Frontiers in Immunology

Received: 29 October 2015

Accepted: 08 February 2016

Published: 23 February 2016

Citation:

Mahnke K, Ring S and Enk AH (2016)

Antibody Targeting of "Steady-State" Dendritic Cells Induces Tolerance

Mediated by Regulatory T Cells.

Front. Immunol. 7:63.

doi: 10.3389/fimmu.2016.00063

\section{Antibody Targeting of "Steady-State" Dendritic Cells Induces Tolerance Mediated by Regulatory T Cells}

\author{
Karsten Mahnke*, Sabine Ring and Alexander H. Enk \\ University Hospital Heidelberg, University of Heidelberg, Heidelberg, Germany
}

Dendritic cells (DCs) are often defined as pivotal inducers of immunity, but these proinflammatory properties only develop after stimulation or ex vivo manipulation of DCs. Under non-inflammatory conditions in vivo, DCs are embedded into a tissue environment and encounter a plethora of self-antigens derived from apoptotic material. This material is transported to secondary lymphoid organs. As DCs maintain their non-activated phenotype in a sterile tissue environment, interaction with $T$ cells will induce rather regulatory $T$ cells than effector $T$ cells. Thus, DCs are not only inducers of immunity but are also critical for maintenance of peripheral tolerance. Therapeutically, intervention for the induction of long-lasting tolerance in several autoimmune conditions may therefore be possible by manipulating DC activation and/or targeting of DCs in their "natural" tissue environment.

Keywords: dendritic cells, regulatory T cells, antibody targeting, DEC205, tolerance

\section{INTRODUCTION}

Mature dendritic cells (DCs) are perfectly equipped with MHC class II-peptide complexes and T cell interacting molecules (immune stimulatory and immune regulatory ones) to regulate $\mathrm{T}$ cell activation and differentiation in secondary lymphoid organs. The DCs act as sentinels in the periphery of the body where they take up antigens and sample the cellular environment. From here, antigens are transported into secondary lymphoid organs, and the subsequent interaction with $\mathrm{T}$ cells is critical for induction of immunity as well as for induction of tolerance. Initial investigations established DCs as pivotal inducers of immunity but with more molecules discovered on the surface of DCs and refined immunological methods, a role in the induction of regulatory T cells (Treg) became clear (1).

The initial experiments on DC functions involved the isolation of DCs from tissues and the ex vivo generation from either bone marrow cells (mouse) or monocytes (human). But these in vitro methods inherently stimulate and activate the developing DCs and when analyzed in T cell stimulation assays, activating capacity was recorded for most DC types.

In contrast to in vitro cultures, in vivo DCs are embedded in a tissue and additional activating stimuli, i.e., TLR ligands and/or trauma have to be applied to DCs in situ in order to mature them and to stimulate their proinflammatory functions. This maturation process is fast (approx. $6 \mathrm{~h}$ ) and effective (2). It induces migration to secondary lymphoid organs and surface expression of MHC class II and T cell costimulatory molecules (3). Therefore, approaches to isolate naïve, non-activated DC directly from tissues is nearly impossible, as manipulation provides enough stimuli to trigger maturation. 


\section{IN VIVO TARGETING OF ANTIGENS TO IMMATURE DCs INDUCE TREG}

A fundamentally different approach from isolating DCs and pulsing them with respective antigens is the technique to load DCs in vivo by antibody targeting. This approach, so far mostly tested in animal models, mimics the in situ situation better. Here, DCs remain embedded into a tissue environment, and no further stimuli, such as trauma and/or infection, are present. In this sterile environment, the antigen is delivered by binding to a DC-specific antigen-uptake receptor. One of the first receptors used in this approach is the DEC205 receptor $(4,5)$. DEC205 is a lectin-like receptor and is closely related to the macrophagemannose receptor. DEC205 recycles through late endosomal MHC class $\mathrm{II}^{+}$compartment and effectively promotes antigen presentation by DCs (6). Therefore, techniques were developed to couple antigens to DEC205-specific antibodies and to inject these conjugates into animals (Figure 1).

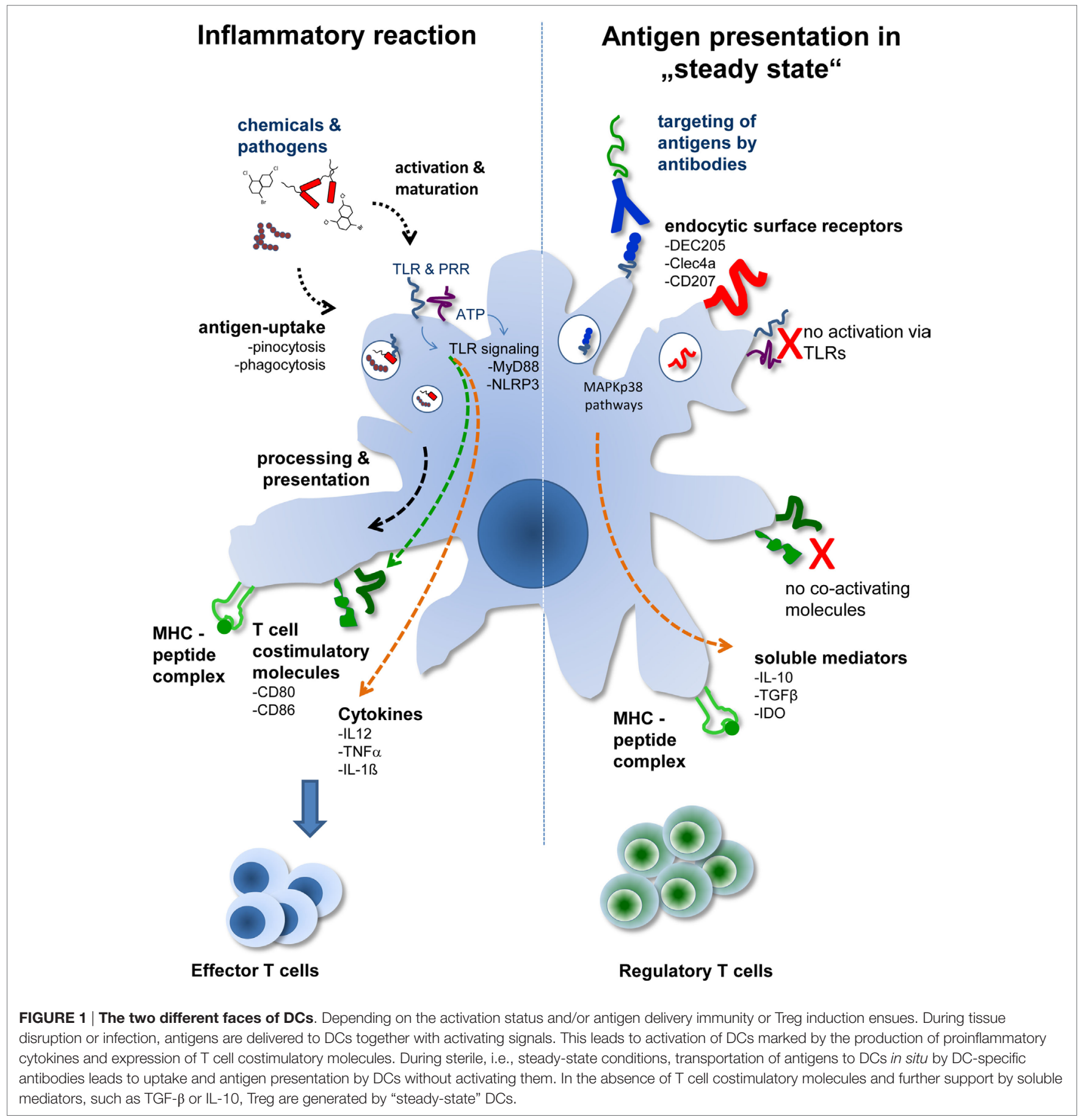


In initial experiments model antigens, such as hen egg lysozyme or ovalbumin, which are frequently used in immunology, were coupled to anti-DEC205 antibodies. In these experiments it was proven that anti-DEC coupled antigens (anti-DEC:antigen) targeted DCs in situ and that the antigens were indeed taken up by the DCs (7-9). This process was highly specific as uptake of anti-DEC:antigen conjugates by Fc receptor expressing cells, such as macrophages, B cells, or granulocytes, was negligible. When anti-DEC:antigen conjugates were injected into animals without further adjuvant the DC phenotype remained non-activated and T cell costimulatory molecules, such as B7.1 and B7.2, showed expression levels comparable to those obtained in DCs from control mice. However, the steady-state DCs were not immunologically inactive, because analysis of antigen-specific $\mathrm{T}$ cell populations in injected mice revealed increased numbers of Treg. These T cells expressed the bona fide Treg markers CD4, CD25, IL-10, and FoxP3, and were able to suppress proliferation of CD4 ${ }^{+}$ $\mathrm{T}$ cells in vivo $(8,10)$. Thus, antigen presentation by steady-state DCs in vivo induces Treg, which offers the possibility to provide a tool for tolerogenic cell therapy in humans.

\section{ANTIBODY TARGETING TO DC AS THERAPEUTIC TOOL IN AUTOIMMUNE DISEASES}

To assess the possibilities of DEC targeting in therapeutic settings, self-antigens were coupled to anti-DEC205 antibodies and conjugates were tested in respective animal models. For instance, anti-DEC205 targeting and Treg induction thereof was tested in a transgenic mouse model for diabetes. In this model, transgenic mice express hemagglutinin (HA) under control of the RIP promoter in pancreatic islets and develop insulinitis (and finally diabetes) upon transfer of HA-specific T cells. When anti-DEC:HA conjugates were used in this model, insulinitis was prevented and diabetes did not develop (11).

Also in another autoimmune model, the experimental allergic encephalitis (EAE), which serves as model for multiple sclerosis, anti-DEC:antigen targeting lead to strong amelioration of the disease. Here, the naturally occurring autoantigen MOG was fused to DEC205-specific single chain fragment variables and mice were treated before and during EAE induction. It was found that IL-10 producing CD4/CD25/FoxP3 ${ }^{+}$Treg were induced, which prevented outbreak of EAE when animal were "tolerized" by anti-DEC:MOG before induction of the disease (12). Moreover, even when anti-DEC:MOG treatment was started after onset of EAE symptoms, a significant amelioration of the disease could be observed. Finally, targeting of the cartilage proteoglycan to DEC205 ${ }^{+}$DCs by means of antibody:antigen conjugates lead to prevention of autoimmune arthritis (13). In summary, these data establish DC targeting via DEC205 as an effective strategy to tolerize against autoantigens in order to protect against autoimmunity.

The DEC205 receptor is in particular suited for DC targeting, as it not only binds antigens to DCs, but also acts as a prototype antigen receptor that actively delivers potential ligands to $\mathrm{MHC}$ class $\mathrm{II}^{+}$compartments. But recently also other surface molecules for DC targeting have been defined on several subsets of DCs. But most of them (e.g., DC-SIGN and CD40) are used for induction of immunity, as they may also possess DC-activating capacity (14). But for CLEC9A mediated targeting, both Treg-inducing and immune stimulatory effects have been described (15-17), and it remains unclear which co-factors and/or differentiation patterns of DCs are involved in regulating these opposite functions. However, some novel candidates have been shown to be able to induce Treg and to lead to tolerance. Among them are CD103, langerin (CD207) (18), triggering receptor on monocytic-like cells (Treml)-4, and Clec4A (19). All are expressed by DCs in varying degrees. However, the most effective DC populations for Treg induction were positive for CD103 and CD207. Interestingly, these molecules are predominantly expressed by tissue residing DCs (e.g., skin and/or gut), which are highly migratory and enter the secondary lymphoid organs on their normal trafficking routes (20).

\section{STEADY-STATE DCs ARE PRONE TO INDUCE TREG-MEDIATED TOLERANCE}

Irrespective of the specificity and the signaling capacity of the antibodies used for targeting, one common denominator for Treg induction by DCs after antibody targeting is their "steady state." This became clear when the same antibody:antigen complexes, which were successfully used for tolerance induction, were injected together with DC-activating stimuli. For instance, when anti-DEC205 antibodies were coupled to tumor antigens, they were able to induce robust anti-tumor immunity when applied together with TLR ligands (21). Similar results were obtained with CLEC9A, which when applied under DC-activating conditions, induces strong humoral and cellular Th1 immunity (16, 17). Therefore, the activation status of the DCs may be critical for decision making on whether tolerance, or immunity ensues after DC-T cell interaction in secondary lymphoid organs.

These opposed functions of otherwise similar DC subsets (as defined by surface marker expression) led to a conceptual view that not particular subsets of DCs but rather non-activated or steady-state DCs are involved in generating Treg and tolerance. Similar to their function as immune stimulators, DCs act as sentinels in the periphery of the body (22). In the absence of inflammation or tissue injury, DCs are constantly exposed to self-proteins. These proteins are taken up and transported by DCs to secondary lymphoid organs. But in contrast to foreign and potentially dangerous antigens, the self-antigens are presented in a tolerogenic fashion to induce Treg and pave the way for further suppressive mechanisms. Altogether, this may be a crucial process to maintain peripheral tolerance (23).

In support of this notion, it has been reported that in peripheral tissues, DCs engulf self-antigens provided by microvesicles, exosomes $(24,25)$, and detritus of epithelial cells lining the gut and lung $(26,27)$. These antigens are transported and presented to $\mathrm{T}$ cells in the draining lymph nodes (28). In particular, apoptotic cells contain a collection of self-antigens and immunity against those antigens would be fatal. Therefore, further safeguards to prevent DC activation and immunity are in place. In case of apoptotic material, specialized receptors, such as CD36 and $\alpha_{v} \beta_{3} / \alpha_{v} \beta_{5}$ 
integrins expressed by DCs, detect components of apoptotic cells and induce intracellular signaling events to prevent maturation and cytokine production $(29,30)$. In more detailed studies, the molecules Gas and Protein 6, expressed by dying cells are recognized by MerTK, leading to signaling via the rather inhibitory STAT3 pathway and simultaneously inhibiting NFkB activation (31). In summary, apoptotic material will keep DCs nonactivated and presentation of the "self-derived" apoptotic cargo will not activate effector T cells. Moreover, the steady-state DCs will induce $\mathrm{CD} 4^{+} \mathrm{CD} 25^{+}$Treg, which in turn will now suppress potentially self-reactive $\mathrm{T}$ cells.

This conceptual view requires a constant flow of non-activated DCs from the periphery to secondary lymphoid organs for the upkeep of Treg activation. If this trafficking is compromised, autoimmunity will develop. That has been demonstrated in a transgenic mouse model, where skin derived DCs are constantly activated by genetic manipulation. Here, severe autoimmunity to skin tissue is induced (32). Moreover, in humans, the incidence of the autoimmune disease systemic lupus erythematosus (SLE) is strongly correlated to a chronically activated phenotype of DCs (33). On the whole, these data suggest that DCs constantly sample the repertoire of peripheral proteins and are an effective source of "self-peptide-MHC" complexes. By presenting these complexes in the steady state, DCs induce Treg and thus suppress potentially self-reactive T cells.

\section{NOT ONLY INDUCE TREG BUT ALSO LIMIT THEIR NUMBERS BY CONVERTING THEM INTO EFFECTORS}

All these data clearly demonstrate that experimentally modified and/or specialized DC subsets exist that are able to induce Treg. However, Treg are not always stable in phenotype and function, as they can convert into proinflammatory cells and loose their suppressive potential. In vivo, during the development of type- 1 and type-2 responses, Treg are exposed to a variety of cytokines and in this process, DCs play a role in driving the conversion of Treg into Th17-like cells either directly or indirectly. A rather indirect and cytokine mediated pathway involves IL-6, which can be secreted by activated DCs. This IL- 6 secretion by DCs may contribute to Treg conversion as natural Treg develop into IL-17 ${ }^{+}$, IFN $\gamma^{+}$ proinflammatory cells after treatment with IL-6 in vitro $(34,35)$.

A direct mechanism by which DCs are involved in converting mouse $\mathrm{CD} 25^{+} \mathrm{Foxp}^{+}$Treg into a proinflammatory cell type is demonstrated by dectin-1. This C-type lectin receptor is normally involved in fungal recognition. But in cocultures of Treg with DCs that have selectively been activated via dectin-1, IL-23 is produced. This leads to conversion of Treg into Th17-like effector $\mathrm{T}$ cells, characterized by the expression of ROR- $\gamma \mathrm{t}$ and the production of IL-17 (36).

In addition to dectin-1, which is rather an antigen-uptake molecule and may therefore signal intracellular after uptake of antigens, surface molecules, such as the T-cell immunoglobalin mucin (TIM-1), may have direct outside-in signaling capacities to turn down Treg induction by DCs by means of Treg conversion. For TIM-1, it has been shown that a high-avidity/agonistic
anti-Tim-1 antibody enhances the immunogenic function of DCs, leading to decreased suppressive function of Treg. At the same time, substantially increased conversion of Treg into proinflammatory IL-17 ${ }^{+} \mathrm{T}$ cells was observed (37).

Likewise, CD18 seems also to be involved in regulating DC-mediated Treg conversion into proinflammatory T cells (38). In a CD18-deficient mouse model, enhanced numbers of Th17 cells were observed resulting in a psoriasis-like phenotype. These data are backed by clinical observations in humans, showing that patients with LAD syndrome (leukocytes do not express functional CD18 in LAD patients) have both elevated levels of Th17 cell and psoriasiform skin disease. Further experiments revealed that this accelerated conversion of Treg into Th17 cells was due to an inadequate DC-Treg interaction via CD18 because blockade of CD18 interactions between DCs and Treg in vitro lead to rapid generation of IL-17+ "ex"-Treg.

However, not only the stability of Treg is influenced by DCs and their respective cytokine environment but also their induction is affected by the context of cytokines and/or pathogens. By broadening the concept that immature DCs are prone to induce Treg, it is conceivable that fully activated and mature DCs induce effectors and may even hamper Treg generation.

For instance, retinoic acid (RA) has been shown to promote conversion of naïve $\mathrm{T}$ cells into Treg cells, presumably by acting on DCs and augmenting TGF- $\beta$. Henceforth, studies have been undertaken to block RA receptors by an antagonist (RARi). RARi significantly suppressed TGF- $\beta$ and IL-10, and enhanced IL-12 production by DC in a tumor model. This protective effect was associated with significant reduction in tumor-infiltrating FoxP3 ${ }^{+}$ and IL- $10^{+}$Treg cells, and a corresponding increase in tumorinfiltrating $\mathrm{CD}^{+}$and $\mathrm{CD}^{+} \mathrm{T}$ cells that secreted IFN- $\gamma$ (39).

Also, vigorously enhanced expression of T-cell costimulatory molecules by DCs provides a means by which Treg activation is suppressed. In the study of Pen et al. (40), DCs were transfected with constitutively active TLR4, CD40 ligand, and the costimulatory molecule CD70. These DCs could partly alleviate Treg inhibition of $\mathrm{CD}^{+} \mathrm{T}$ cells, which was further accompanied by a decrease in CD27 and CD25 expression on Treg. Moreover, an increase in the expression of T-bet and secretion of IFN- $\gamma$, tumor necrosis factor (TNF)- $\alpha$, and IL-10 was recorded, suggesting a shift of the Treg phenotype toward a Th1 phenotype.

Finally, even without molecular transfection approaches, CpG-ODN-stimulated DCs exhibited pivotal proinflammatory functions, as in a Leishmania donovani model intracellular parasitic growth was abolished by these CpG-stimulated DCs (41). Alongside, it was observed that DC vaccination resulted in significant decreased Treg numbers. Moreover, the remaining Treg were partly defective in TGF $\beta$ secretion and were affected in IP-10 signaling.

Although the exact molecular mechanism are not clear yet, evidence exists that p38 expression in DCs is crucial for regulating their Treg-activating and/or Treg-converting functions $(42,43)$. Therefore, small molecules tampering with p38 pathways activation in DCs may be useful to shift the Treg-Th17 balance in vivo.

Vice versa, in Treg expression of SOCS-1 (44), TRAF6 (45) and other transcriptions factors, such as Runx1, CNS2, and Cbf $\beta$ 
(46) is important for maintenance of their suppressive phenotype, because absence of these factors in murine knock out models resulted in increased conversion of Treg into Th17-like cells. Thus, future investigations have to address as to how DC subsets and/ or surface molecules thereof interfere and trigger those signaling pathways in Treg.

In aggregate, these findings indicate that not only the generation of Treg but also their stability of phenotype is regulated by DCs. DC-derived cytokines, such as IL-6 and IL-23, as well as surface molecules are important to regulate Treg conversion into Th17 cells and are able to shift the balance between effector and Treg toward an enhanced immune response.

\section{EX VIVO MANIPULATION OF DCs FOR THE INDUCTION OF TREG}

\section{Role of Cytokines}

In line with the concept that immature DCs induce Treg and tolerance, attempts can be made to stabilize the immature DC phenotype by manipulation of the cytokine environment. One important cytokine in this context is interleukin (IL)-10. After exposure of DCs to IL-10 in vitro culture systems, the cells display reduced surface expression of MHC class I and II molecules and reduced expression of $\mathrm{T}$ cell costimulatory molecules of the $\mathrm{B} 7$ family as compared to their untreated counterparts. But not only surface molecules change, also the release of proinflammatory cytokines, i.e., IL-1 $\beta$, IL- 6 , and TNF $\alpha$ and most markedly IL-12, is abolished after IL-10 treatment (47). However, all of these effects could only be induced in immature DCs. In contrast, mature DCs are insensitive to IL-10 and display a stable phenotype in the presence of IL-10. Therefore, for therapeutically use, IL-10 has to be added to in vitro culture systems very early on and/or in vivo elevated IL-10 levels have to be present once pre-DC are present in the respective tissues. The proof that those immature DCs do not only possess weak proinflammatory properties but also actively induce $\mathrm{T}$ cells with regulatory properties comes from observations in human melanoma. For example, IL-10 producing metastases are able to convert DCs into tolerogenic DC, which induce anergy in melanoma or alloantigen-specific $\mathrm{CD}^{+}$and $\mathrm{CD} 8^{+} \mathrm{T}$ cells $(48,49)$. But these anergic $\mathrm{T}$ cells were not just inactive, instead they acted as "bystander" suppressors that actively curbed anti-melanoma $\mathrm{T}$ cell activation (50). Moreover, in mice overexpressing IL-10, DCs displayed a remarkably immature phenotype (51) and the appearance of the immature DCs was accompanied by substantially increased numbers of Treg in the spleens of these mice. This suggests that IL-10 plays an important role in rendering DCs not merely immature but also modifies their ability to induce Treg in vivo. To exploit the effects of IL-10 on DCs for Treg induction, IL-10 modulated DCs were injected in the murine model for EAE and in a GVHD model. In both instances, substantial amelioration of the disease and immune suppression by regulatory active $\mathrm{T}$ cells was observed $(49,52)$. Likewise, in a mouse model of asthma, the injection of IL-10-treated DCs lead to increased differentiation of bona fide Treg from effector T cells, which were able to ameliorate asthmatic incidence in house dust mite allergic mice $(53,54)$. Thus, these data establish IL-10 as a critical agent for induction of a Treginducing DC phenotype. But moreover, IL-10 may also facilitate the cross talk between Treg and DCs, since it acts simultaneously on both cell types. For example, Misra et al. (55) have shown that DCs cocultured with Treg remain in an immature state as judged by surface marker expression. These "Treg-exposed" DCs were inferior in induction of T cell proliferation and produced significant amounts of IL-10, which (i) maintains Treg function in a paracrine fashion and (ii) keeps DCs immature via an autocrine loop.

\section{Role of Vitamin D3}

Beyond the IL-10 effects, also non-cytokine immune modulators are active in keeping DCs functional as "Treg-inducers." For instance, vitamin D [VitD3: $1,25(\mathrm{OH})_{2} \mathrm{D} 3$ ] treated DCs display a rather immature phenotype as they express low MHC class II, low amounts of $\mathrm{T}$ cell costimulatory molecules, and high production of IL-10 (56). This clearly tolerogenic phenotype of DC exert their immune regulatory functions by different means. First, it has been shown that VitD3 DCs are inactive in priming $\mathrm{CD}^{+}$and $\mathrm{CD}^{+}$ $\mathrm{T}$ cells. Second, they are inducers of apoptosis in effector T cells and thirdly they are able to induce allo- and autoantigen-specific Treg from naïve $\mathrm{CD} 4^{+} \mathrm{T}$ cells, which were able to block diabetes in a non-obese diabetes animal model (57-59).

In case of VitD3 DCs, TNF- $\alpha$ plays a critical role as co-inducer of Treg. Although TNF $\alpha$ has a long standing track record for being proinflammatory, it has been shown to act tolerogenic on DCs. First observations by Menges et al. showed that TNF $\alpha$ matured DC are able to ameliorate multiple sclerosis symptoms in a murine EAE model (60). Further observations with human cells broadened these findings, by showing that VitD3 increased the amounts of membrane-bound TNF $\alpha$ in DCs and that in particular, this membrane-bound TNF $\alpha$ is critical for the induction of Treg (53). In addition to VitD3 alone, DCs have also been treated in combination with Dexamethason. These combinatorially treated DCs exhibited a more stable tolerogenic phenotype in vivo and were more potent in inducing Treg in a murine colitis model (61).

\section{CONCLUSION}

In summary, these data show that agents, which actively block DC maturation, augment the ability of the DCs to induce Treg. Therefore, the "default" function of immature DCs is to maintain sufficient numbers of Treg in the periphery of the body. Prevention of DC maturation as well as antigen loading of otherwise untouched steady-state DCs in vivo may therefore be one future therapeutic approach to induce long-lasting tolerance in different autoimmune diseases.

\section{AUTHOR CONTRIBUTIONS}

KM and AHE wrote the paper. SR prepared figures and helped writing the paper.

\section{FUNDING}

This work was funded by the DFG (TRR156) by grants to KM and AE. Publication costs were supported by DFG and RuprechtKarls-Universität Heidelberg within the funding programme Open Access Publishing. 


\section{REFERENCES}

1. Mahnke K, Johnson TS, Ring S, Enk AH. Tolerogenic dendritic cells and regulatory T cells: a two-way relationship. J Dermatol Sci (2007) 46:159-67. doi:10.1016/j.jdermsci.2007.03.002

2. Pierre P, Turley SJ, Gatti E, Hull M, Meltzer J, Mirza A, et al. Developmental regulation of MHC class II transport in mouse dendritic cells. Nature (1997) 388:787-92. doi:10.1038/42039

3. Inaba K, Turley S, Iyoda T, Yamaide F, Shimoyama S, Reis E, et al. The formation of immunogenic major histocompatibility complex class II-peptide ligands in lysosomal compartments of dendritic cells is regulated by inflammatory stimuli. J Exp Med (2000) 191:927-36. doi:10.1084/jem.191.6.927

4. Jiang W, Swiggard WJ, Heufler C, Peng M, Mirza A, Steinman RM, et al. The receptor DEC-205 expressed by dendritic cells and thymic epithelial cells is involved in antigen processing. Nature (1995) 375:151-5. doi:10.1038/375151a0

5. Guo M, Gong S, Maric S, Misulovin Z, Pack M, Mahnke K, et al. A monoclonal antibody to the DEC-205 endocytosis receptor on human dendritic cells. Hum Immunol (2000) 61:729-38. doi:10.1016/S0198-8859(00)00144-0

6. Mahnke K, Guo M, Lee S, Sepulveda H, Swain SL, Nussenzweig M, et al. The dendritic cell receptor for endocytosis, DEC-205, can recycle and enhance antigen presentation via major histocompatibility complex class II-positive lysosomal compartments. J Cell Biol (2000) 151:673-84. doi:10.1083/ jcb.151.3.673

7. Hawiger D, Inaba K, Dorsett Y, Guo M, Mahnke K, Rivera M, et al. Dendritic cells induce peripheral $\mathrm{T}$ cell unresponsiveness under steady state conditions in vivo. J Exp Med (2001) 194:769-79. doi:10.1084/jem.194.6.769

8. Mahnke K, Qian Y, Knop J, Enk AH. Induction of CD4+/CD25+ regulatory $\mathrm{T}$ cells by targeting of antigens to immature dendritic cells. Blood (2003) 101:4862-9. doi:10.1182/blood-2002-10-3229

9. Maksimow M, Miiluniemi M, Marttila-Ichihara F, Jalkanen S, Hanninen A. Antigen targeting to endosomal pathway in dendritic cell vaccination activates regulatory T cells and attenuates tumor immunity. Blood (2006) 108:1298-305. doi:10.1182/blood-2005-11-008615

10. Yamazaki S, Dudziak D, Heidkamp GF, Fiorese C, Bonito AJ, Inaba K, et al. CD8+ CD205+ splenic dendritic cells are specialized to induce Foxp3+ regulatory T cells. J Immunol (2008) 181:6923-33. doi:10.4049/ jimmunol.181.10.6923

11. Bruder D, Westendorf AM, Hansen W, Prettin S, Gruber AD, Qian Y, et al. On the edge of autoimmunity: T-cell stimulation by steady-state dendritic cells prevents autoimmune diabetes. Diabetes (2005) 54:3395-401. doi:10.2337/ diabetes.54.12.3395

12. Ring S, Maas M, Nettelbeck DM, Enk AH, Mahnke K. Targeting of autoantigens to DEC205(+) dendritic cells in vivo suppresses experimental allergic encephalomyelitis in mice. JImmunol (2013) 191:2938-47. doi:10.4049/ jimmunol.1202592

13. Spiering R, Margry B, Keijzer C, Petzold C, Hoek A, Wagenaar-Hilbers J, et al. DEC205+ dendritic cell-targeted tolerogenic vaccination promotes immune tolerance in experimental autoimmune arthritis. J Immunol (2015) 194:4804-13. doi:10.4049/jimmunol.1400986

14. Fehres CM, Van Beelen AJ, Bruijns SC, Ambrosini M, Kalay H, Bloois L, et al. In situ delivery of antigen to DC-SIGN $(+)$ CD14(+) dermal dendritic cells results in enhanced CD8(+) T-cell responses. J Invest Dermatol (2015) 135:2228-36. doi:10.1038/jid.2015.152

15. Joffre OP, Sancho D, Zelenay S, Keller AM, Reis E, Sousa C. Efficient and versatile manipulation of the peripheral CD4+ T-cell compartment by antigen targeting to DNGR-1/CLEC9A. Eur J Immunol (2010) 40:1255-65. doi:10.1002/eji.201040419

16. Kato Y, Zaid A, Davey GM, Mueller SN, Nutt SL, Zotos D, et al. Targeting antigen to Clec9A primes follicular Th cell memory responses capable of robust recall. J Immunol (2015) 195:1006-14. doi:10.4049/jimmunol.1500767

17. Li J, Ahmet F, Sullivan LC, Brooks AG, Kent SJ, De Rose R, et al. Antibodies targeting Clec9A promote strong humoral immunity without adjuvant in mice and non-human primates. Eur J Immunol (2015) 45:854-64. doi:10.1002/ eji.201445127

18. Ocadlikova D, Trabanelli S, Salvestrini V, Ciciarello M, Evangelisti C, Lecciso $\mathrm{M}$, et al. CD103 marks a subset of human CD34+-derived langerin+ dendritic cells that induce T-regulatory cells via indoleamine 2,3-dioxygenase-1. Exp Hematol (2015) 43(268-276):e265. doi:10.1016/j.exphem.2014.12.007
19. Idoyaga J, Fiorese C, Zbytnuik L, Lubkin A, Miller J, Malissen B, et al. Specialized role of migratory dendritic cells in peripheral tolerance induction. J Clin Invest (2013) 123:844-54. doi:10.1172/JCI65260

20. Azukizawa H, Dohler A, Kanazawa N, Nayak A, Lipp M, Malissen B, et al. Steady state migratory RelB+ langerin+ dermal dendritic cells mediate peripheral induction of antigen-specific CD4+ CD25+ Foxp3+ regulatory $\mathrm{T}$ cells. Eur J Immunol (2011) 41:1420-34. doi:10.1002/eji.201040930

21. Mahnke K, Qian Y, Fondel S, Brueck J, Becker C, Enk AH. Targeting of antigens to activated dendritic cells in vivo cures metastatic melanoma in mice. Cancer Res (2005) 65:7007-12. doi:10.1158/0008-5472.CAN-05-0938

22. Mahnke K, Knop J, Enk AH. Induction of tolerogenic DCs: 'you are what you eat'. Trends Immunol (2003) 24:646-51. doi:10.1016/j.it.2003.09.012

23. Luckashenak N, Schroeder S, Endt K, Schmidt D, Mahnke K, Bachmann MF, et al. Constitutive crosspresentation of tissue antigens by dendritic cells controls CD8+ T cell tolerance in vivo. Immunity (2008) 28:521-32. doi:10.1016/j. immuni.2008.02.018

24. Harshyne LA, Watkins SC, Gambotto A, Barratt-Boyes SM. Dendritic cells acquire antigens from live cells for cross-presentation to CTL. J Immunol (2001) 166:3717-23. doi:10.4049/jimmunol.166.6.3717

25. Thery C, Duban L, Segura E, Veron P, Lantz O, Amigorena S. Indirect activation of naive CD4+ T cells by dendritic cell-derived exosomes. Nat Immunol (2002) 3:1156-62. doi:10.1038/ni854

26. Holt PG, Schon-Hegrad MA, Oliver J, Holt BJ, Mcmenamin PG. A contiguous network of dendritic antigen-presenting cells within the respiratory epithelium. Int Arch Allergy Appl Immunol (1990) 91:155-9. doi:10.1159/000235107

27. Huang FP, Platt N, Wykes M, Major JR, Powell TJ, Jenkins CD, et al. A discrete subpopulation of dendritic cells transports apoptotic intestinal epithelial cells to T cell areas of mesenteric lymph nodes. J Exp Med (2000) 191:435-44. doi:10.1084/jem.191.3.435

28. Inaba K, Turley S, Yamaide F, Iyoda T, Mahnke K, Inaba M, et al. Efficient presentation of phagocytosed cellular fragments on the major histocompatibility complex class II products of dendritic cells. J Exp Med (1998) 188:2163-73. doi:10.1084/jem.188.11.2163

29. Urban BC, Willcox N, Roberts DJ. A role for CD36 in the regulation of dendritic cell function. Proc Natl Acad Sci U S A (2001) 98:8750-5. doi:10.1073/ pnas. 151028698

30. Verbovetski I, Bychkov H, Trahtemberg U, Shapira I, Hareuveni M, Ben-Tal O, et al. Opsonization of apoptotic cells by autologous iC3b facilitates clearance by immature dendritic cells, down-regulates DR and CD86, and up-regulates CC chemokine receptor 7. J Exp Med (2002) 196:1553-61. doi:10.1084/ jem.20020263

31. Wallet MA, Sen P, Flores RR, Wang Y, Yi Z, Huang Y, et al. MerTK is required for apoptotic cell-induced T cell tolerance. J Exp Med (2008) 205:219-32. doi:10.1084/jem.20062293

32. Mehling A, Loser K, Varga G, Metze D, Luger TA, Schwarz T, et al. Overexpression of CD40 ligand in murine epidermis results in chronic skin inflammation and systemic autoimmunity. J Exp Med (2001) 194:615-28. doi:10.1084/jem.194.5.615

33. Blanco P, Palucka AK, Gill M, Pascual V, Banchereau J. Induction of dendritic cell differentiation by IFN-alpha in systemic lupus erythematosus. Science (2001) 294:1540-3. doi:10.1126/science.1064890

34. Xu L, Kitani A, Fuss I, Strober W. Cutting edge: regulatory T cells induce CD4+CD25-Foxp3- T cells or are self-induced to become Th17 cells in the absence of exogenous TGF-beta. J Immunol (2007) 178:6725-9. doi:10.4049/ jimmunol.178.11.6725

35. Zheng SG, Wang J, Horwitz DA. Cutting edge: Foxp3+CD4+CD25+ regulatory T cells induced by IL- 2 and TGF-beta are resistant to Th17 conversion by IL-6. J Immunol (2008) 180:7112-6. doi:10.4049/jimmunol.180.11.7112

36. Osorio F, Leibundgut-Landmann S, Lochner M, Lahl K, Sparwasser T, Eberl G, et al. DC activated via dectin-1 convert Treg into IL-17 producers. Eur J Immunol (2008) 38:3274-81. doi:10.1002/eji.200838950

37. Xiao S, Zhu B, Jin H, Zhu C, Umetsu DT, DeKruyff RH, et al. Tim-1 stimulation of dendritic cells regulates the balance between effector and regulatory $\mathrm{T}$ cells. Eur J Immunol (2011) 416:1539-49. doi:10.1002/eji.201040993

38. Singh K, Gatzka M, Peters T, Borkner L, Hainzl A, Wang H, et al. Reduced CD18 levels drive regulatory T cell conversion into Th17 cells in the CD18hypo PL/J mouse model of psoriasis. J Immunol (2013) 190:2544-53. doi:10.4049/ jimmunol.1202399 
39. Galvin KC, Dyck L, Marshall NA, Stefanska AM, Walsh KP, Moran B, et al. Blocking retinoic acid receptor- $\alpha$ enhances the efficacy of a dendritic cell vaccine against tumours by suppressing the induction of regulatory $\mathrm{T}$ cells. Cancer Immunol Immunother (2013) 62:1273-82. doi:10.1007/ s00262-013-1432-8

40. Pen JJ, De Keersmaecker B, Maenhout SK, Van Nuffel AM, Heirman C, Corthals J, et al. Modulation of regulatory $\mathrm{T}$ cell function by monocyte-derived dendritic cells matured through electroporation with mRNA encoding CD40 ligand, constitutively active TLR4, and CD70. J Immunol (2013) 191:1976-83. doi:10.4049/jimmunol.1201008

41. Majumder S, Bhattacharjee A, Paul Chowdhury B, Bhattacharyya Majumdar S, Majumdar S. Antigen-pulsed CpG-ODN-activated dendritic cells induce host-protective immune response by regulating the $\mathrm{T}$ regulatory cell functioning in Leishmania donovani-infected mice: critical role of CXCL10. Front Immunol (2014) 4:261. doi:10.3389/fimmu.2014.00261

42. Lu Y, Zhang M, Wang S, Hong B, Wang Z, Li H, et al. p38 MAPK-inhibited dendritic cells induce superior antitumour immune responses and overcome regulatory T-cell-mediated immunosuppression. Nat Commun (2014) 5:4229-39. doi:10.1038/ncomms5229

43. Soukup K, Halfmann A, Le Bras M, Sahin E, Vittori S, Poyer F, et al. The MAPK-activated kinase MK2 attenuates dendritic cell-mediated Th1 differentiation and autoimmune encephalomyelitis. J Immunol (2015) 195:541-52. doi:10.4049/jimmunol.1401663

44. Takahashi R, Nishimoto S, Muto G, Sekiya T, Tamiya T, Kimura A, et al. SOCS1 is essential for regulatory $\mathrm{T}$ cell functions by preventing loss of Foxp3 expression as well as IFN- $\gamma$ and IL-17A production. J Exp Med (2011) 208:2055-67. doi:10.1084/jem.20110428

45. Muto G, Kotani H, Kondo T, Morita R, Tsuruta S, Kobayashi T, et al. TRAF6 is essential for maintenance of regulatory $\mathrm{T}$ cells that suppress Th2 type autoimmunity. PLoS One (2013) 8:e74639. doi:10.1371/journal. pone.0074639

46. Guo J, Zhou X. Regulatory T cells turn pathogenic. Cell Mol Immunol (2015) 12:525-32. doi:10.1038/cmi.2015.12

47. Steinbrink K, Wolfl M, Jonuleit H, Knop J, Enk AH. Induction of tolerance by IL-10-treated dendritic cells. J Immunol (1997) 159:4772-80.

48. Steinbrink K, Jonuleit H, Muller G, Schuler G, Knop J, Enk AH. Interleukin10-treated human dendritic cells induce a melanoma-antigen-specific anergy in CD8(+) $\mathrm{T}$ cells resulting in a failure to lyse tumor cells. Blood (1999) 93:1634-42.

49. Sato K, Yamashita N, Baba M, Matsuyama T. Modified myeloid dendritic cells act as regulatory dendritic cells to induce anergic and regulatory T cells. Blood (2003) 101:3581-9. doi:10.1182/blood-2002-09-2712

50. Steinbrink K, Graulich E, Kubsch S, Knop J, Enk AH. CD4(+) and CD8(+) anergic T cells induced by interleukin-10-treated human dendritic cells display antigen-specific suppressor activity. Blood (2002) 99:2468-76. doi:10.1182/ blood.V99.7.2468

51. Wakkach A, Fournier N, Brun V, Breittmayer JP, Cottrez F, Groux H. Characterization of dendritic cells that induce tolerance and $\mathrm{T}$ regulatory 1 cell differentiation in vivo. Immunity (2003) 18:605-17. doi:10.1016/ S1074-7613(03)00113-4
52. Muller G, Muller A, Tuting T, Steinbrink K, Saloga J, Szalma C, et al. Interleukin-10-treated dendritic cells modulate immune responses of naive and sensitized T cells in vivo. J Invest Dermatol (2002) 119:836-41. doi:10.1046/j.1523-1747.2002.00496.x

53. Kleijwegt FS, Laban S, Duinkerken G, Joosten AM, Zaldumbide A, Nikolic $\mathrm{T}$, et al. Critical role for TNF in the induction of human antigen-specific regulatory T cells by tolerogenic dendritic cells. J Immunol (2010) 185:1412-8. doi:10.4049/jimmunol.1000560

54. Kleijwegt FS, Jansen DT, Teeler J, Joosten AM, Laban S, Nikolic T, et al. Tolerogenic dendritic cells impede priming of naive CD8(+) $\mathrm{T}$ cells and deplete memory CD8(+) T cells. Eur J Immunol (2013) 43:85-92. doi:10.1002/ eji.201242879

55. Misra N, Bayry J, Lacroix-Desmazes S, Kazatchkine MD, Kaveri SV. Cutting edge: human $\mathrm{CD} 4+\mathrm{CD} 25+\mathrm{T}$ cells restrain the maturation and antigen-presenting function of dendritic cells. J Immunol (2004) 172:4676-80. doi:10.4049/jimmunol.172.8.4676

56. Ferreira GB, Vanherwegen AS, Eelen G, Gutierrez AC, Van Lommel L, Marchal K, et al. Vitamin D3 induces tolerance in human dendritic cells by activation of intracellular metabolic pathways. Cell Rep (2015) 10:711-25. doi:10.1016/j.celrep.2015.01.013

57. Piemonti L, Monti P, Sironi M, Fraticelli P, Leone BE, Dal Cin E, et al. Vitamin D3 affects differentiation, maturation, and function of human monocyte-derived dendritic cells. J Immunol (2000) 164:4443-51. doi:10.4049/ jimmunol.164.9.4443

58. Adorini L. Tolerogenic dendritic cells induced by vitamin D receptor ligands enhance regulatory T cells inhibiting autoimmune diabetes. Ann N Y Acad Sci (2003) 987:258-61. doi:10.1111/j.1749-6632.2003.tb06057.x

59. Unger WW, Laban S, Kleijwegt FS, Van Der Slik AR, Roep BO. Induction of Treg by monocyte-derived DC modulated by vitamin D3 or dexamethasone: differential role for PD-L1. Eur J Immunol (2009) 39:3147-59. doi:10.1002/ eji.200839103

60. Menges M, Rossner S, Voigtlander C, Schindler H, Kukutsch NA, Bogdan $\mathrm{C}$, et al. Repetitive injections of dendritic cells matured with tumor necrosis factor alpha induce antigen-specific protection of mice from autoimmunity. J Exp Med (2002) 195:15-21. doi:10.1084/jem.20011341

61. Pedersen AE, Schmidt EG, Gad M, Poulsen SS, Claesson MH. Dexamethasone/1alpha-25-dihydroxyvitamin D3-treated dendritic cells suppress colitis in the SCID T-cell transfer model. Immunology (2009) 127:354-64. doi:10.1111/j.1365-2567.2008.02996.x

Conflict of Interest Statement: The authors declare that the research was conducted in the absence of any commercial or financial relationships that could be construed as a potential conflict of interest.

Copyright (c) 2016 Mahnke, Ring and Enk. This is an open-access article distributed under the terms of the Creative Commons Attribution License (CC BY). The use, distribution or reproduction in other forums is permitted, provided the original author(s) or licensor are credited and that the original publication in this journal is cited, in accordance with accepted academic practice. No use, distribution or reproduction is permitted which does not comply with these terms. 